\title{
Is Fistulotomy with Marsipulization more Effective than Fistulectomy alone for Low Fistula in Ano?
}

\author{
Danish Aslam ${ }^{1} \quad$ Farhan Zaheer $^{1}$ Sarush Ahmed Siddiqui ${ }^{1}$ Foad Ali Moosa ${ }^{1}$ Shafaq Naseer ${ }^{1}$ \\ Rabia Arsalan ${ }^{1}$ Muhammed Osama ${ }^{1}$ \\ ${ }^{1}$ Department of General Surgery, Dow University of Health Sciences, \\ Karachi, Pakistan \\ J Coloproctol 2021;41(4):355-360. \\ Address for correspondence Sarush Ahmed Siddiqui, MBBS, \\ Department: General Surgery, Institute/University/Hospital: Dow \\ University of Health Sciences, Saddar, Karachi, Pakistan \\ (e-mail: siddiquisarush@gmail.com).
}

\begin{abstract}
Keywords

- fistula in ano

- fistulotomy with marsupialization

- fistulectomy

Background Fistula in ano is a very common perianal condition seen in outpatient departments. Fistulotomy and fistulectomy are two conventional options of surgery. The present study is designed to observe wound healing time and mean postoperative pain score in the comparison of outcome of the fistulectomy to fistulotomy with marsupialization.

Methods This prospective randomized trial was conducted in the surgical department of the Civil Hospital Karachi for a period of 12 months, in which 60 patients with low anal fistula were divided into 2 groups. Thirty patients in group $A$ were treated with fistulectomy, and 30 in group B were treated with fistulotomy with marsupialization. The postoperative pain severity was assessed after 24 hrs through a visual analogue scale and on weekly and fortnightly follow-ups for 6 weeks. Wound healing was assessed by clinical examination on weekly and fortnightly follow-ups for 6 weeks to estimate the mean healing time.

Results The mean pain score was significantly lower in group $B$ in comparison to group $A(3.6 \pm 1.99$ versus $2.40 \pm 1.52 ; p=0.01)$. The mean wound healing time was shorter in group B in comparison to group A ( $4.23 \pm 0.77$ versus $5.80 \pm 0.41$ weeks; $p=0.0005)$.

Conclusion Fistulotomy with marsupialization is a simple, easy, and more effective method than fistulectomy for the treatment of simple perianal fistula.
\end{abstract}

\section{Introduction}

Fistula in ano is a common perianal condition seen in daily surgical outpatient practice. It is an abnormal tract lined by granulation tissue between two epithelial surfaces, namely anorectal mucosa and perianal skin. Mostly affected are men and young-to-middle-aged adults. ${ }^{1}$ The majority of anal fistulas arise from anal crypts infections or in association with many disease processes, though a small fraction of cases are secondary to Crohn disease, tuberculosis, sexually transmitted diseases, or malignancy. ${ }^{2}$ Fistula in ano, according to Park's classification, is classified into intersphincteric, transsphincteric, supra sphincteric, or extra sphincteric fistula. ${ }^{3}$ The mainstay of management is the eradication of sepsis received

February 1, 2021

accepted after revision

June 15, 2021
DOI https://doi.org/

$10.1055 / \mathrm{s}-0041-1736642$.

ISSN 2237-9363.

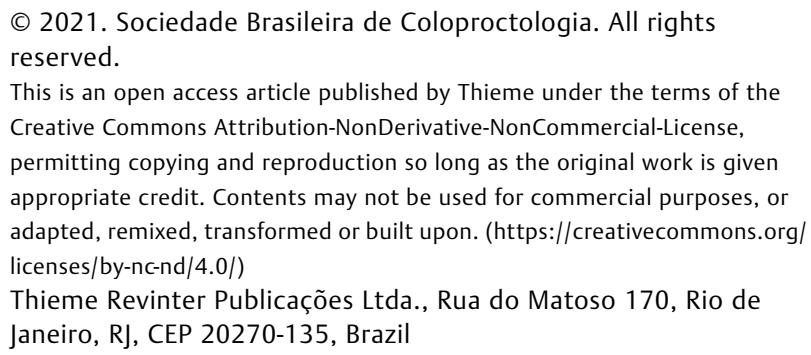


with preservation of anorectal function and reduction of the rate of recurrence. ${ }^{4}$ Fistulotomy and fistulectomy are two conventional options for surgery. A fistulectomy involves complete excision of the fistulous tract, thereby eliminating the risk of missing secondary tracts and providing complete tissue for histopathological examination. A fistulotomy lays open the fistulous tract, thus leaving smaller epithelized wounds, which hastens the wound healing. Marsupialization of the fistulotomy wounds can reduce the healing time further. ${ }^{5}$ In the present study, we have compared the efficacy in fistulectomy to that of fistulotomy with marsupialization of edges in low fistula in ano concerning mean wound healing time and mean postoperative pain. This would help us to determine which of this techniques is simpler, easier to perform, leads to early healing of wound, and has a reduced risk of incontinence and recurrence.

\section{Materials and Methods}

This randomized control trial was conducted on 60 patients treated in the surgical department of the Civil Hospital Karachi from June 2019 to June 2020. Ethical clearance was obtained from the institutional ethical board of Duke University Health System (DUHS), and consent from all patients was taken. Sixty patients were selected by nonprobability consecutive sampling technique. They were further divided into 2 groups, A and B, of 30 patients each. Low fistula in ano was defined as the fistula that had a single external and internal opening involving the lower anal canal.

\section{Inclusion and Exclusion Criteria}

The study included all male and female patients of age 18 years and above up to age 65 years, having a low anal fistula for a duration of 3 months. Patients with complex fistulas; high fistula; comorbidities such as tuberculosis, Crohn disease, and malignancies; and those associated with abnormalities such as anal fissures, anal masses, and hemorrhoids, were excluded from the study.

\section{Data Collection and Randomization}

All patients were selected after complete clinical history of duration of symptoms, painful defecation, perianal discharge, incontinence, previous surgery along with history of associated comorbidities. Detailed clinical examination included perineal inspection, palpation, digital rectal examination and proctoscopy. Appropriate investigations such as complete blood picture and viral markers were conducted. Patients were randomly allocated to two groups by computer-generated number list, namely group A (fistulectomy) and group B (fistulotomy with marsupialization). All data was recorded on predesigned performa which includes demographic data such as as name, age, gender, pain scores, and wound healing time.

\section{Surgical Technique}

All procedures were performed by a consultant surgeon with more than 3 years' experience. The patient was operated on under spinal anesthesia. The anorectal examination was done under anesthesia to verify the clinical findings. A dye test with methylene blue was performed to know the patency of fistulous tracts. A probe was passed through an external opening. In fistulotomy with marsupialization, the tract was laid open over the probe and the tract edges were sutured to the wound with edges with polyglycolic acid interrupted sutures. In fistulectomy, the whole tract was excised around the probe and sent for histopathology.

\section{Postoperative Care and Follow-up}

Postoperative patients were given ciprofloxacin, metronidazole, and a 50-mg diclofenac sodium tablet twice a day for 5 days. Laxatives were also prescribed to avoid constipation during the early wound healing time. Patients were discharged on the 1st postoperative day and advised regarding oral medications, sitz bath twice a day and after each bowel movement, local hygiene, dressings, and follow-ups. Postoperative pain severity was assessed after 24 hrs through a visual analog scale on a scale of 0 to 10 , on weekly and fortnightly follow-ups for 6 weeks. Complete wound healing was defined as complete epithelialization of the wound with no evidence of external fistula opening or discharge. Wound healing was assessed by clinical examination on weekly and fortnightly follow-ups for 6 weeks to estimate the mean healing time. The patients were observed for recurrence of the fistula and incontinence during the follow-up period. Development of incontinence was assessed using the 3-point Likert scale ( 0 , never; 1 , sometimes; 2 , always) according to inability to distinguish between gas and stool, difficulty in holding gas, and soiling of undergarments. No patients were lost to follow-up.

\section{Data Analysis}

The data were analyzed using IBM SPSS Statistics for Windows, Version 22.0 software (IBM Corp., Armonk, NY, USA). The sample size was calculated on Open Epi, Version 3. Sixteen patients in each group were required to achieve a power of study of $80 \%$ and a confidence interval of $95 \%$. However, 30 patients in each group were included to decrease sampling error. The mean and standard deviation was calculated for quantitative variables like age, postoperative pain, and wound healing time in weeks. Frequencies and percentages were calculated for gender, diabetes mellitus, and hypertension. The Student $t$-test was applied to compare the mean pain score and mean healing time in both groups. Stratification was done for effect modifiers such as age, gender, and diabetes mellitus. Student $t$-test was applied poststratification. A $p<0.05$ value was considered statistically significant.

\section{Results}

A total of 60 patients clinically diagnosed with low anal fistula of 3 months duration were divided into 2 groups. Thirty patients in group A were treated with fistulectomy, and 30 in group B were treated with fistulotomy with marsupialization. The mean age of the patients was $37.20 \pm 10.65$ years [95\%C\%: $34.45-39.95]$ with a male-to-female ratio of $5: 1$. The 
Table 1 Descriptive statistics of age according to groups $(n=60)$

\begin{tabular}{|l|l|l|l|}
\hline Statistics & $\begin{array}{l}\text { Group A } \\
\mathbf{N}=\mathbf{3 0}\end{array}$ & $\begin{array}{l}\text { Group B } \\
\mathbf{N}=\mathbf{3 0}\end{array}$ \\
\hline Mean & 36.40 & 38.00 \\
\hline Stadard deviation & 7.26 & 13.29 \\
\hline $\begin{array}{l}\text { 95\% confidence } \\
\text { interval for mean }\end{array}$ & Lower bound & 33.69 & 33.04 \\
\cline { 2 - 4 } & Upper bound & 39.11 & 42.96 \\
\hline
\end{tabular}

average age of the patients concerning group A was $36.40 \pm 7.26$, while the average age of the patients in group B was found to be $38.00 \pm 13.29$, as shown in - Table 1. The mean postoperative pain score was significantly higher in group A than in group B [3.6 \pm 1.99 versus $2.40 \pm 1.52$; $p=0.01$ ] by the 6 th week, as presented in - Figure 1. It was also observed that the wound healing time was longer in group A than in group B $(4.23 \pm 0.77$ versus $5.80 \pm 0.41$ weeks; $p=0.0005$ ), as shown in -Figure 2. Stratification analysis was performed, and it was observed that the mean healing time was lower in group B than in group A for all stratified groups. Postoperative pain and mean healing time in both groups were compared with respect to age, gender, and diabetic status of the patient using stratification analysis. At age group $\leq 40$ years, the mean postoperative pain score was found out to be significantly higher in group $A$ than in group B ( $3.85 \pm 1.99$ versus $2.00 \pm 2.08 ; p=0.013)$, and the mean healing time was also significantly higher in group $A$ than in group B $(5.85 \pm 0.36$ versus $4.50 \pm 0.52$ weeks; $p=0.0005$ ). For the age group $>40$ years, mean postoperative pain was found out to be higher in group $B(2.67 \pm 0.97)$ when compared with group A $(2.00 \pm 1.15)$; however, this difference did not reach statistical significance $(p=0.242)$. The mean healing time in patients of age group $>40$ was higher in group A $(5.50 \pm 0.57)$ than in group B $(4.06 \pm 0.87)$, and this difference reached a statistical sig-

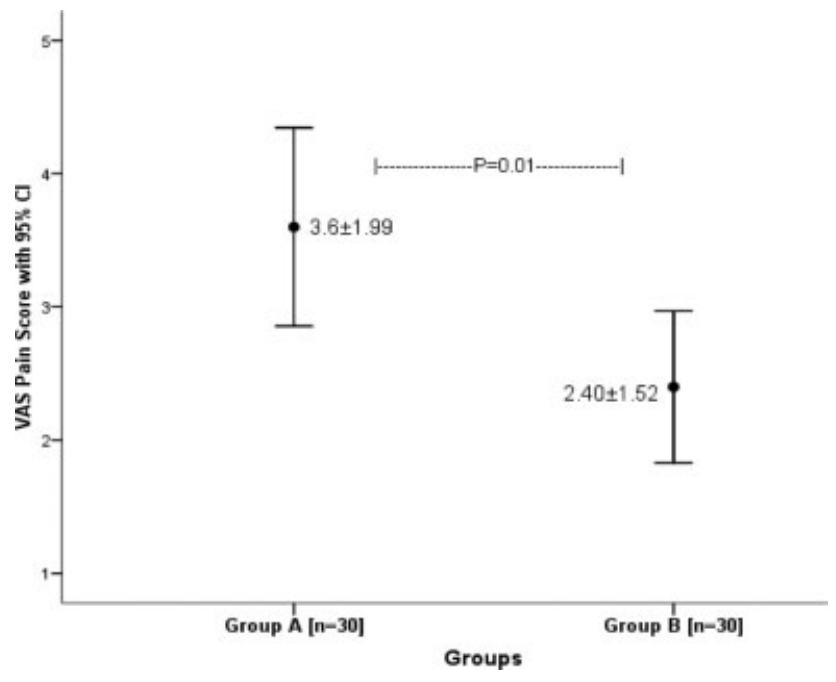

Fig. 1 Comparison of mean postoperative pain score between groups at $6^{\text {th }}$ week $(n=60)$

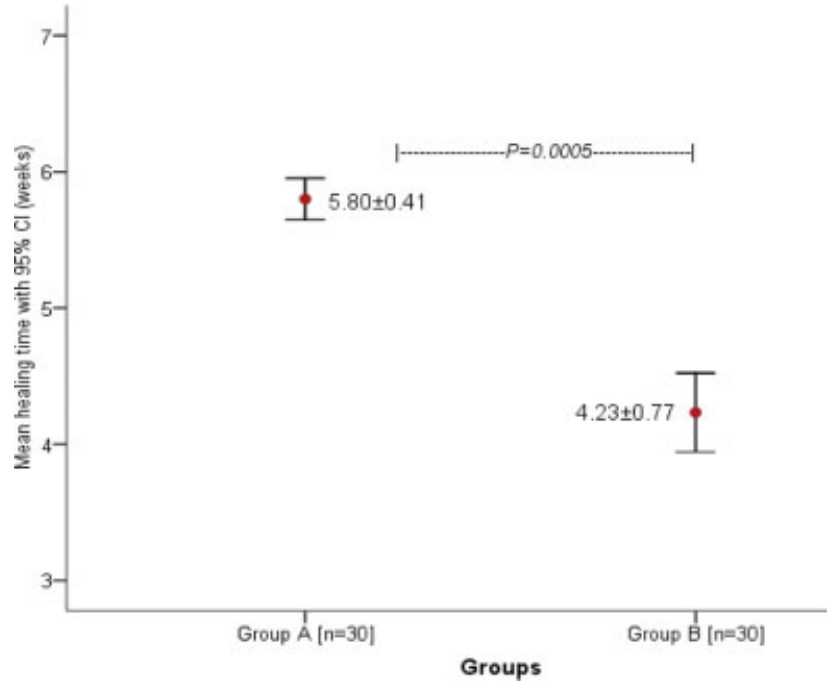

Fig. 2 Comparison of mean postoperative healing time between groups $(n=60)$

nificance with a $p$-value of 0.0005 , as shown in - Table 2 . In males, the mean postoperative pain score was significantly higher in group A than group B ( $3.55 \pm 1.92$ vs, $2.29 \pm 1.51$; $p=0.012$ ), and mean healing time was also significantly higher in group A than in group B $(5.82 \pm 0.39$ versus $4.25 \pm 0.79$ week; $p=0.0005)$. In females, there was no difference in the mean postoperative pain score noted, however, the mean healing time was found to be significantly higher in group A than in group B $(5.75 \pm 0.46$ versus $4.00 \pm 0.00 ; p=0.001$ ), as shown in - Table 3. In patients without diabetes mellitus, the mean postoperative pain score was significantly higher in group A than in group B $(3.64 \pm 2.06$ versus $2.15 \pm 1.49 ; p=0.004)$, and the mean healing time was also significantly higher in group $A$ than in group B $(5.86 \pm 0.36$ versus $4.19 \pm 0.69$ weeks; $p=0.0005)$. No statistically significant difference in the mean postoperative pain score and mean healing time was observed amongst patients with diabetes mellitus in the two groups, as shown in -Table 4 .

\section{Discussion}

Fistula in ano is a common surgical problem with an incidence of abscesses and fistula being 1 to 2 per 10,000 population. It is twice as common in males than in females. The common age of presentation is between 20 and 45 years. ${ }^{6}$ The main objective of management of low fistula in ano is to remove the internal opening along with the epithelized fistula tract, while preserving the function of the anal sphincter. Several factors, like etiology, the anatomy of fistula, severity of symptoms, comorbidity, and experience of the surgeon, must be taken into account. ${ }^{7}$

High fistula in ano is difficult to treat since the conventional procedure may lead to the division of most of the anal sphincter muscles, resulting in incontinence. Several techniques are used for treatment of high fistula in ano, like the placement of seton, fibrin glue, advancement flap, and 
A Comparative Randomized Trial Aslam et al.

Table 2 Comparison of mean pain score and healing time between groups stratified by age

\begin{tabular}{|c|c|c|c|c|c|c|c|c|}
\hline \multirow[t]{2}{*}{ Age groups (Years) } & \multirow[t]{2}{*}{ Outcome } & \multirow[t]{2}{*}{ Groups } & \multirow[t]{2}{*}{$\mathrm{n}$} & \multirow[t]{2}{*}{ Mean } & \multirow[t]{2}{*}{ Standard deviation } & \multicolumn{2}{|c|}{$\begin{array}{l}95 \% \text { confidence } \\
\text { interval for mean }\end{array}$} & \multirow[t]{2}{*}{$P$-value } \\
\hline & & & & & & $\begin{array}{l}\text { Lower } \\
\text { bound }\end{array}$ & $\begin{array}{l}\text { Upper } \\
\text { bound }\end{array}$ & \\
\hline \multirow[t]{4}{*}{$\leq 40$} & \multirow[t]{2}{*}{ Pain } & Group A & 26 & 3.85 & 1.99 & 3.04 & 4.65 & \multirow[t]{2}{*}{0.013} \\
\hline & & Group B & 12 & 2.00 & 2.08 & 0.67 & 3.33 & \\
\hline & \multirow{2}{*}{$\begin{array}{l}\text { Healing } \\
\text { time }\end{array}$} & Group A & 26 & 5.85 & 0.36 & 5.70 & 5.99 & \multirow[t]{2}{*}{0.0005} \\
\hline & & Group B & 12 & 4.50 & 0.52 & 4.17 & 4.83 & \\
\hline \multirow[t]{4}{*}{$>40$} & \multirow[t]{2}{*}{ Pain } & Group A & 4 & 2.00 & 1.15 & 0.16 & 3.84 & \multirow[t]{2}{*}{0.242} \\
\hline & & Group B & 18 & 2.67 & 0.97 & 2.18 & 3.15 & \\
\hline & \multirow[t]{2}{*}{ Healing time } & Group A & 4 & 5.50 & 0.57 & 4.58 & 6.42 & \multirow[t]{2}{*}{0.0005} \\
\hline & & Group B & 18 & 4.06 & 0.87 & 3.62 & 4.49 & \\
\hline
\end{tabular}

Table 3 Comparison of mean pain score and healing time between groups stratified by gender

\begin{tabular}{|c|c|c|c|c|c|c|c|c|}
\hline \multirow[t]{2}{*}{ Gender } & \multirow[t]{2}{*}{ Outcome } & \multirow[t]{2}{*}{ Groups } & \multirow[t]{2}{*}{$\mathrm{n}$} & \multirow[t]{2}{*}{ Mean } & \multirow[t]{2}{*}{ Standard deviation } & \multicolumn{2}{|c|}{$\begin{array}{l}\text { 95\% confidence } \\
\text { interval for mean }\end{array}$} & \multirow[t]{2}{*}{$P$-value } \\
\hline & & & & & & $\begin{array}{l}\text { Lower } \\
\text { bound }\end{array}$ & $\begin{array}{l}\text { Upper } \\
\text { bound }\end{array}$ & \\
\hline \multirow[t]{4}{*}{ Male } & \multirow[t]{2}{*}{ Pain } & Group A & 22 & 3.55 & 1.92 & 2.69 & 4.40 & \multirow[t]{2}{*}{0.012} \\
\hline & & Group B & 28 & 2.29 & 1.51 & 1.70 & 2.87 & \\
\hline & \multirow[t]{2}{*}{ Healing time } & Group A & 22 & 5.82 & 0.39 & 5.64 & 5.99 & \multirow[t]{2}{*}{0.0005} \\
\hline & & Group B & 28 & 4.25 & 0.79 & 3.94 & 4.56 & \\
\hline \multirow[t]{4}{*}{ Female } & \multirow[t]{2}{*}{ Pain } & Group A & 8 & 3.75 & 2.31 & 1.81 & 5.69 & \multirow[t]{2}{*}{0.887} \\
\hline & & Group B & 2 & 4.00 & 0.00 & 4.00 & 4.00 & \\
\hline & \multirow[t]{2}{*}{ Healing time } & Group A & 8 & 5.75 & 0.46 & 5.36 & 6.14 & \multirow[t]{2}{*}{0.001} \\
\hline & & Group B & 2 & 4.00 & 0.00 & 4.00 & 4.00 & \\
\hline
\end{tabular}

Table 4 Comparison of mean pain score and healing time between groups stratified by diabetic status of the patients

\begin{tabular}{|c|c|c|c|c|c|c|c|c|}
\hline \multirow[t]{2}{*}{ DM } & \multirow[t]{2}{*}{ Outcome } & \multirow[t]{2}{*}{ Groups } & \multirow[t]{2}{*}{$\mathrm{n}$} & \multirow[t]{2}{*}{ Mean } & \multirow[t]{2}{*}{ Standard deviation } & \multicolumn{2}{|c|}{$\begin{array}{l}95 \% \text { confidence in- } \\
\text { terval for mean }\end{array}$} & \multirow[t]{2}{*}{$P$-value } \\
\hline & & & & & & $\begin{array}{l}\text { Lower } \\
\text { bound }\end{array}$ & $\begin{array}{l}\text { Upper } \\
\text { bound }\end{array}$ & \\
\hline \multirow[t]{4}{*}{ Yes } & \multirow[t]{2}{*}{ Pain } & Group A & 2 & 3.00 & 0.00 & 3.00 & 3.00 & \multirow[t]{2}{*}{0.842} \\
\hline & & Group B & 4 & 4.00 & 0.00 & 4.00 & 4.00 & \\
\hline & \multirow[t]{2}{*}{ Healing time } & Group A & 2 & 5.00 & 0.00 & 5.00 & 5.00 & \multirow[t]{2}{*}{0.633} \\
\hline & & Group B & 4 & 4.50 & 1.29 & 2.45 & 6.55 & \\
\hline \multirow[t]{4}{*}{ No } & \multirow[t]{2}{*}{ Pain } & Group A & 28 & 3.64 & 2.06 & 2.84 & 4.44 & \multirow[t]{2}{*}{0.004} \\
\hline & & Group B & 26 & 2.15 & 1.49 & 1.55 & 2.76 & \\
\hline & \multirow[t]{2}{*}{ Healing time } & Group A & 28 & 5.86 & 0.36 & 5.72 & 6.00 & \multirow[t]{2}{*}{0.0005} \\
\hline & & Group B & 26 & 4.19 & 0.69 & 3.91 & 4.47 & \\
\hline
\end{tabular}


fistulotomy with the reconstruction of anal sphincters. ${ }^{8}$ By using a staged procedure without cutting the anal sphincter, most fistulas heal with good functional results. ${ }^{9}$

Both fistulectomy and fistulotomy have commonly been utilized for the management of low fistula in ano. Fistulectomy is considered to be associated with longer healing times due to larger defects after surgery and a higher risk of incontinence. In contrast, fistulotomy is considered more effective in treating low fistula in ano when compared with fistulectomy. ${ }^{10}$ Various techniques have been employed in this regard to reduce the time required for healing fistula wounds, which eventually helps in reducing the inconvenience and cost of treatment to the patient. Marsupialization, which is not an essential component of fistulotomy has been postulated to improve the duration of wound healing by reducing the un-epithelialized raw tissue left after fistulotomy. ${ }^{11}$

In our study, the mean healing time in group B (fistulotomy with marsupialization) was $4 \pm 1.53$ weeks, whereas the mean healing time in group A (fistulotomy) was $5 \pm 2.89$ weeks ( $p$-value $=0.0002$ ), consistent with the finding of various studies conducted earlier. In a study by Kronborg ${ }^{10}$ on 47 patients, the mean healing time for the fistulotomy group was 5 weeks (range: 7-85 days), and it was shorter than the mean healing time for the fistulectomy group, which was 6 weeks (range: 26-116 days). Similarly, in a study conducted by Kamal et al. ${ }^{12}$ on 76 patients, it was observed that the mean healing time for the fistulotomy group was 4.5 weeks (range: $21-36$ days), which was shorter than the time for healing in the fistulectomy group, with a mean of 5.5 weeks (range: 32-46 days). The finding of studies conducted by Ho et al. ${ }^{13}$ and Pescatori et al. ${ }^{14}$ (2005) also support the benefits of marsupialization after fistulotomy when compared with fistulotomy.

Pain is one of the important side-effects of perianal surgery and a source of distress and inconvenience to the patient. Various authors have studied the effects of fistulectomy and fistulotomy on postoperative pain. Pescatori et al. ${ }^{14}$ and Anan et al. ${ }^{15}$ in their studies compared the effects of fistulectomy with fistulotomy and marsupialization observed that the mean pain score was higher in the group with fistulotomy and marsupialization; however, it was not significant on statistical analysis. Though, in one of these studies' marsupialization suture had to be removed in a patient due to persistent pain. ${ }^{14}$

Similarly, studies comparing the effects of fistulectomy with fistulotomy and marsupialization have also reported no significant difference in the mean score of postoperative pain in both groups. Jain at al., ${ }^{16}$ in their randomized trial comparing fistulectomy with fistulotomy and marsupialization, observed that although the mean pain score was higher in fistulotomy with marsupialization group, there was no statistical difference between the pain score of both groups. Chalya et al. ${ }^{17}$ observed there was no statistical difference between the mean postoperative pain score in both the groups.

In contrast to these studies, in our study, the mean pain score was significantly higher in the fistulectomy group as compared with the fistulotomy group ( $p$-value $<0.0005)$. The probable explanation for this finding may be a larger wound of fistulectomy compared with fistulotomy with marsupialization that would have resulted in overall higher pain scores experienced by these patients. Similar findings were observed by Bhatti et al. ${ }^{18}$ in the study comparison of fistulectomy with fistulotomy. Furthermore, a higher degree of postoperative pain was observed in fistulectomy group. In another randomized trial, postoperative pain score on the visual analog score was high in the fistulectomy group $(2.68 \pm 0.62)$ as compared with the fistulotomy group $(2.23 \pm 0.50)$ after 1 week of follow up. Similar findings were noted after the $4^{\text {th }}$ week of follow up which was statistically significant ( $p$-value 0.026). ${ }^{19}$

Most of the studies have reported anal incontinence and recurrence of fistula after fistulectomy and with fistulectomy and marsupialization ${ }^{14-17}$; however, this complication was not observed in the patients in our study since all the patients selected for this study had a simple low fistula in ano, while patients with high tract, complex, and recurrent fistulas were excluded.

The design of our study had some limitations which may have altered the outcome of the study. First, the duration of follow-up needed to assess the development of recurrence and incontinence in patients is beyond the scope of this study and requires further research to observe such long-term complications. Second, a small sample size from a single institution is another limitation of this study. Lastly, the study included patients with simple, low anal fistula and may have resulted in fewer complications and better postoperative outcomes observed in patients of both groups.

\section{Conclusion}

The present study demonstrated that Fistulotomy with marsupialization is an easy, and effective method for the treatment of simple perianal fistula, with less postoperative pain and less time needed for wound healing than fistulectomy with a similar incidence of immediate and early postoperative complications, for all stratified groups.

\section{Statement of Ethics}

The subjects used in the study have given their consent, and the study protocol was approved by the institute's committee on human research. IRB number: IRB1281/DUHS/Approval/2019

\section{Authors Contribution}

All authors played a role in designing the study, analyzing and intepreting the data, drafting the study, and ensuring authenticity of the data.

\section{Source of Funding}

There is no potential source of funding to declare.

\section{Conflict of interests}

The authors have no potential conflict of interests to declare. 


\section{References}

1 Scoma JA, Salvati EP, Rubin RJ. Incidence of fistulas subsequent to anal abscesses. Dis Colon Rectum 1974;17(03):357-359

2 Poggio J. Fistula-in-ano. Medscape Mar 27, 2020. Available from: https://emedicine.medscape.com/article/190234-overview\#a24

3 Parks AG, Gordon PH, Hardcastle JD. A classification of fistula-inano. Br J Surg 1976;63(01):1-12

4 Wang Q, He Y, Shen J. The best surgical strategy for anal fistula based on a network meta-analysis. Oncotarget 2017;8(58):99075-99084

5 Wexner SD. Practice parameters for treatment of fistulain-anosupporting documentation. The Standards Practice Task Force, The American Society of Colon and Rectal Surgeons. Dis Colon Rectum 1996;39(12):1363-1372

6 Tyler KM, Aarons CB, Sentovich SM. Successful sphincter-sparing surgery for all anal fistulas. Dis Colon Rectum 2007;50(10):1535-1539

7 Shawki S, Wexner SD. Idiopathic fistula-in-ano. World J Gastroenterol 2011;17(28):3277-3285

8 Köckerling F, Alam NN, Narang SK, Daniels IR, Smart NJ. Treatment of fistula-in-ano with fistula plug? A review under special consideration of the technique. Front Surg 2015;2:55

9 Munir A, Falah SQ. Management of high fistula in ano with cutting seton. Gomal J Med Sci. 2014;12:210-212

10 Kronborg O. To lay open or excise a fistula-in-ano: a randomized trial. Br J Surg 1985;72(12):970

11 Vogel JD, Johnson EK, Morris AM, et al. Clinical Practice Guideline for the Management of Anorectal Abscess, Fistula-in-Ano, and Rectovaginal Fistula. Dis Colon Rectum 2016;59(12):1117-1133
12 Kamal ZB. Fistulotomy versus fistulectomy as a primary treatment of low fistula in ano. Iraqi Postgrad Med J 2012;11:510-515

13 Ho YH, Tan M, Leong AF, Seow-Choen F. Marsupialization of fistulotomy wounds improves healing: a randomized controlled trial. Br J Surg 1998;85(01):105-107

14 Pescatori M, Ayabaca SM, Cafaro D, Iannello A, Magrini S. Marsupialization of fistulotomy and fistulectomy wounds improves healing and decreases bleeding: a randomized controlled trial. Colorectal Dis 2006;8(01):11-14

15 Anan M, Emile SH, Elgendy H, et al. Fistulotomy with or without marsupialisation of wound edges in treatment of simple anal fistula: a randomised controlled trial. Ann R Coll Surg Engl 2019; 101(07):472-478

16 Jain BK, Vaibhaw K, Garg PK, Gupta S, Mohanty D. Comparison of a fistulectomy and a fistulotomy with marsupialization in the management of a simple anal fistula: a randomized, controlled pilot trial. J Korean Soc Coloproctol 2012;28(02):78-82

17 Chalya PL, Mabula JB. Fistulectomy versus fistulotomy with marsupialisation in the treatment of low fistula-in- ano: a prospective randomized controlled trial. Tanzan J Health Res 2013;15(03):193-198

18 Bhatti Y, Fatima S, Shaikh GS, Shaikh S. Fistulotomy versus fistulectomy in the treatment of low fistula in ano. Rawal Med J 2011;36(04):284-286

19 Ahmed T, Khan I, Iqbal MM, Khan MI, Shah SH, Parveen S. Comparison of Fistulectomy with Fistulotomy in Low Fistula in Ano. Journal of Surgery Pakistan (International) 2016;21:3 